\title{
Effects of thyrotropin suppression on lumbar bone mineral density in postmenopausal women with differentiated thyroid carcinoma
}

This article was published in the following Dove Press journal:

OncoTargets and Therapy

\author{
Pei Zhang' \\ Hui $X i^{2}$ \\ Ruihong Yan ${ }^{3}$ \\ 'Department of Endocrinology, \\ Liaocheng People's Hospital, \\ Liaocheng, Shandong, China; \\ ${ }^{2}$ Department of Oncology, Liaocheng \\ People's Hospital, Liaocheng, \\ Shandong, China; ${ }^{3}$ Department of \\ Nuclear Medicine, Liaocheng People's \\ Hospital, Liaocheng, Shandong, China
}

Correspondence: Hui Xi

Department of Oncology, Liaocheng

People's Hospital, Dongchang Xi Road 67,

Liaocheng 252000, Shandong, China

Tel +866358276110

Email xihuil9750627@I26.com
Purpose: The aim of this study was to evaluate the effect of postoperative thyroid-stimulating hormone suppression (TSHS) on bone mineral density (BMD) in Chinese postmenopausal women with differentiated thyroid carcinoma (DTC).

Patients and methods: A total of 225 postmenopausal women with DTC who had received TSHS were included in the study. Postmenopausal women with postoperative DTC undergoing thyroid residual ablation or metastasis treatment between 2009 and 2015 were enrolled and followed up for 2 years. They were divided into two groups: TSHS group (median thyroid-stimulating hormone $[\mathrm{TSH}]<0.3 \mu \mathrm{IU} / \mathrm{mL}$ ) and postmenopausal control group (median TSH $>0.3 \mu \mathrm{IU} / \mathrm{mL}$ ). Lumbar 1-4 BMD levels were measured by a dual-energy X-ray absorptiometry (DXA) at baseline and 6, 12 and 24 months. All patients had calcium and vitamin D supplementation. The diagnosis of osteopenia $(-1 \mathrm{SD}>\mathrm{T}>-2.5 \mathrm{SD})$ and osteoporosis $(\mathrm{T}<-2.5 \mathrm{SD})$ was made according to WHO guidelines.

Results: Thyroid cancers included 211 papillary carcinomas and 14 follicular carcinomas. One hundred and fifty-four patients were in the TSHS group, and 71 patients were in the nonsuppressed TSH group (postmenopausal controls). No significant differences were found in the BMD of the lumbar spine between baseline and after 6, 12 and 24 months, pre and post treatment in TSHS and non-suppressed TSH patients. Compared with pre-TSHS, there was a reduction in the BMD of $1.9 \%$ in the lumbar spine at the 2-year follow-up. Significant difference in the number of osteopenia and osteoporosis patients at 24 months $\left(\chi^{2}=2.88, P=0.004\right)$ was found between the TSHS (103/152) and postmenopausal control (32/68) groups. TSHS is not a significant risk of bone loss, but it is the incidence of osteopenia in postmenopausal women with DTC

Conclusion: Our 2-year follow-up data indicated that TSHS had little effect on BMD in postmenopausal women with DTC. Large population with at least 5-year follow-up should be further investigated. BMD in postmenopausal women with DTC should be followed up regularly.

Keywords: differentiated thyroid carcinoma, thyroid-stimulating hormone suppression, bone mineral density, postmenopausal women, osteopenia

\section{Introduction}

Osteoporosis is a common disease characterized by reduction in bone mineral density (BMD). Increasing age, female sex and postmenopausal status are the common causes of osteoporosis. Osteoporosis in women is mainly caused by estrogen deficiency following menopause which is a potential risk factor for bone fracture and results in rapid bone loss in postmenopausal women. ${ }^{1,2}$ In addition to the abovementioned information, an overdose of thyroid hormone may also negatively correlate with the 
BMD of the lumbar spine. Differentiated thyroid carcinoma (DTC) is the most frequently occurring endocrine cancer, and its incidence has been increasing worldwide during recent decades. DTC has a favorable long-term prognosis in general. Most patients with DTC are well managed with a combined treatment of radical surgery, radioiodine (RAI) ablation and thyroid hormone replacement with an overall good survival. Thyroid-stimulating hormone suppression (TSHS) with levothyroxine $\left(\mathrm{LT}_{4}\right)$ is important to reduce the risk of tumor recurrence of DTC, after surgery and iodine-131 ( $\left.{ }^{131} \mathrm{I}\right),{ }^{3,4}$ because thyroid-stimulating hormone (TSH) is a trophic hormone that can stimulate the growth of cells derived from thyroid follicular epithelium. Therefore, the recommended TSH level is below $0.1 \mu \mathrm{IU} / \mathrm{mL}$ or slightly below or slightly above the lower reference range according to patients' risk stratification. However, TSHS may be a potential risk factor for the cardiovascular system and BMD. ${ }^{5-7}$ The negative effect of TSHS on BMD in postmenopausal women with DTC remains conflicting. ${ }^{7-18}$ It is well known that the loss of BMD may correlate with the risk of fractures in postmenopausal women. ${ }^{6,7}$ Postmenopausal DTC patients under TSHS may have bone loss in lumbar which was investigated in the study.

\section{Patients and methods}

\section{Patients}

Between June 2008 and June 2016, from all the patients with DTC who were referred to our department requiring ${ }^{131}$ I treatment or regular follow-up, postmenopausal women with DTC were included according to the following criteria: 1) history of total thyroidectomy and ablative RAI treatment for DTC and the histological results were papillary or follicular thyroid cancer; 2) treatment with $\mathrm{LT}_{4}$ at suppressive doses of TSH for at least 6 months after RAI and 3) BMDs were tested at least twice (at study entry and/or one during 6-24 months prior to the study). The exclusion criteria were as follows: patients with 1) metabolic osteopathy; 2) malabsorption syndrome; 3) rheumatic disease; 4) severe liver or renal disease; 5) other malignant tumor diseases; 6) bone metastasis originated from DTC or other malignancies; 7) Grave's disease; 8) ischemic heart disease or arrhythmia and 9) the use of medications that might affect bone metabolism including estrogen, glucocorticoids, bisphosphonate, denosumab, selective estrogen receptor modulators (SERMs), teriparatide, strontium ranelate, diuretics, and lithium. This study was approved by the institutional review board of Liaocheng People's Hospital research ethics committee, and all subjects gave written informed consent.

\section{$\mathrm{LT}_{4}$ treatment}

All patients with DTC underwent $\mathrm{LT}_{4}$ treatment according to the Chinese Thyroid Association (CTA) guidelines for the initial treatment and long-term management of DTC. ${ }^{3}$ The CTA guidelines recommend a similar degree of TSHS to the American Thyroid Association guidelines based on the risk stratification of DTC. Serum TSH levels of $<0.1 \mu \mathrm{IU} / \mathrm{mL}$ are recommended for patients with persistent disease; serum TSH levels of $0.1-0.5 \mu \mathrm{IU} / \mathrm{mL}$ for patients free of disease, but who originally presented with high-risk disease; and a lower TSH normal range $(0.3-2.0 \mu \mathrm{IU} / \mathrm{mL})$ for those patients at low risk of recurrence. ${ }^{3}$

\section{Thyroid hormone and biochemical test}

TSH was measured using a time-resolved immunofluorometric assay (Anytest; SYM-BIO Lifescience Co., Ltd., Shanghai, China). The normal reference range of TSH is $0.3-4.6 \mu \mathrm{IU} / \mathrm{mL}$ in our laboratory. Free thyroxine (FT4) and triiodothyronine (FT3) were also analyzed using the same method as TSH with the normal reference ranges of 6.6-24.8 and 3.3-8.5 pmol/L. Patients were divided into the TSHS (median TSH $<0.3 \mu \mathrm{IU} / \mathrm{mL}$ ) and the non-suppressed groups (median TSH $>0.3 \mu \mathrm{IU} / \mathrm{mL}$ ). Calcium was measured by automated techniques with the normal range of 2.19-2.56 $\mathrm{mmol} / \mathrm{L}$.

\section{Assessment of vertebral BMD}

Areal BMD $\left(\mathrm{g} / \mathrm{cm}^{2}\right)$ was measured at the lumbar spine, L1 to L4, using dual-energy X-ray absorptiometry (DXA; version 13.20; enCORETM 2009; GE Healthcare Bio-Sciences Corp., Piscataway, NJ, USA) according to the manufacturer's protocol. The normative database of BMD was Asian population data provided by the manufacturer. BMDs were analyzed on the same regions of interest as those used for BMD in the lumbar spine. Subjects were measured on the same densitometer, using the same software, scan speed and technologist. Measurements of BMD were performed at baseline and 6 months for all subjects; 12- and 24-month follow-ups may also be performed in the majority of patients.

\section{Statistical analyses}

Values with normal distributions were expressed as mean $\pm \mathrm{SD}$. To analyze the significance of intergroup differences, the chi-squared test was used for categorical data and the unpaired or paired $t$-test was used for continuous variables. Paired $t$-test was used to compare the BMD at 
baseline and follow-up. The correlation of BMD with FT3 and FT4 was performed by Pearson analysis.

\section{Results}

\section{Patients' clinical characteristics}

Out of 232 postmenopausal DTC patients treated in our hospital, seven patients were excluded for the following: bone metastases of DTC in four patients and bisphosphonate treatment for osteoporosis in three patients. Finally, 225 patients met the inclusion criteria and were included. One hundred and fifty-four patients were in the TSHS group, and 71 patients were in the non-suppressed TSH group (control group). The serum TSH was significantly lower in TSHS patients $(0.09 \pm 0.01)$ than that in non-suppressed patients $(0.63 \pm 0.08)$. The other baseline characteristics of the patients in the two groups were comparable (Table 1). Thyroid cancers included 211 papillary carcinomas and 14 follicular carcinomas. Most of the included patients were employees. (157/225, 70\%). DTC patients with TSHS ( $\mathrm{n}=154)$ had T1N1M0 (n=25), TxN0-1M1 ( $\mathrm{n}=40)$, T2N0-1M0 ( $=28)$, T3N0-1M0 ( $\mathrm{n}=36)$ and T4N0-1M0-1 ( $\mathrm{n}=25$; lung metastases). In 71 people in the control group, 16 had T1N0-1M0, 25 had TxN0-1M1, ten had T2N0-1M0, 15 had T3N0-1M0 and five had T4N0-1M0-1 (lung metastases). No nicotine abuses and chronic obstructive lung disease were found in the included patients.

The radioactivity of iodine for thyroid residual ablation was from 50 to $100 \mathrm{mCi}$ according to patients' restaging after surgery. The dose of lymph node and lung metastases was 120 and $150-200 \mathrm{mCi}$, respectively. Most of the patients had one-time RAI treatment $(\mathrm{n}=128)$. Patients with lymph node or lung metastases received two to six times ${ }^{131} \mathrm{I}$ treatment. A total of five patients with osteoporosis diagnosed at 6-, 12and 24 month follow-up were treated with bisphosphonate and therefore were excluded.

\section{Comparisons of BMD in the lumbar spine between TSHS and non-suppressed patients with DTC}

No significant differences were found in the BMD of the lumbar spine between baseline and after 6,12 and 24 months, pre and post treatment in TSHS patients with DTC and postmenopausal controls. The BMD $\left(\mathrm{g} / \mathrm{cm}^{2}\right)$ values in the TSHS $(\mathrm{n}=154)$ and control $(\mathrm{n}=71)$ groups were $1.03 \pm 0.17$ and $0.98 \pm 0.16,1.04 \pm 0.14$ and $1.04 \pm 0.17,1.03 \pm 0.15$ and $1.06 \pm 0.27$, respectively, at 6-, 12 and 24-month follow-up without significant difference $(t=1.37$, $P=0.17 ; t=-0.128, P=0.89 ; t=-0.547, P=0.89$; Table 2 ). Compared with pre-TSHS treatment, there was a reduction in the BMD of $1.9 \%$ in the lumbar spine at the 2-year follow-up.

Significant difference in the number of osteopenia and osteoporosis patients was found at 24 months $\left(\chi^{2}=2.88\right.$, $P=0.004)$ between the TSHS (103/152) and postmenopausal control (32/68) groups, and no significant difference in the number of osteopenia and osteoporosis patients was found at 6 months ( $72 / 154$ vs $\left.35 / 70, \chi^{2}=0.45, P=0.65\right)$ and 12 months (71/154 vs 30/69, $\chi^{2}=0.36, P=0.72$; Table 3 ).

Pearson analysis found that there was no significant correlation between BMD and FT3 $(r=-0.054, P=0.437)$ and BMD and FT4 $(r=0.003, P=0.986$; Figures 1 and 2, respectively).

\section{Discussion}

TSHS with $\mathrm{LT}_{4}$ is important to reduce the risk of tumor recurrence of DTC after surgery and ${ }^{131} \mathrm{I} .^{3-5}$ The effect of TSHS on BMD in postmenopausal patients with DTC remains conflicting and needs to be further clarified by large population. In addition, to the best of our knowledge, Chinese data have not published yet. Therefore, in the study, we evaluated the effect of TSHS on BMD in postmenopausal women with DTC.

Table I Patients' clinical characteristics

\begin{tabular}{l|l|l|l|l}
\hline & TSHS & $\begin{array}{l}\text { Postmenopausal } \\
\text { controls }\end{array}$ & $t$-value & $P$-value \\
\hline Number & 154 & 71 & & \\
TSH $(\mu \mathrm{lU} / \mathrm{mL})$ & $0.09 \pm 0.01$ & $0.63 \pm 0.08$ & -10.57 & 0.00 \\
Age (years) & $55.58 \pm 8.1$ & $55.94 \pm 8.09$ & -0.3 & 0.76 \\
Height $(\mathrm{cm})$ & $161.4 \pm 5.83$ & $161.44 \pm 5.43$ & -0.05 & 0.96 \\
Weight $(\mathrm{kg})$ & $62.81 \pm 10.75$ & $63.03 \pm 9.79$ & -0.14 & 0.89 \\
Body mass index & $23.51 \pm 3.54$ & $23.17 \pm 4.02$ & 0.6 & 0.55 \\
FT3 (pmol/L) & $6.30 \pm 2.09$ & $4.46 \pm 1.23$ & 8.36 & 0.00 \\
FT4 (pmol/L) & $22.24 \pm 7.14$ & $17.35 \pm 3.15$ & 7.16 & 0.00 \\
Calcium (mmol/L) & $2.24 \pm 0.15$ & $2.21 \pm 0.17$ & 1.26 & 0.21 \\
Vitamin D 25 & $24.57 \pm 17.79$ & $25.56 \pm 19.44$ & -0.14 & 0.89 \\
BMD $\left(\mathrm{g} / \mathrm{cm}^{2}\right)$ & $1.05 \pm 0.16$ & $1.06 \pm 1.21$ & -0.315 & 0.753 \\
\hline
\end{tabular}

Note: Data are presented as mean \pm SD unless otherwise specified.

Abbreviations: BMD, bone mineral density; FT3, triiodothyronine; FT4, free thyroxine; TSHS, thyroid-stimulating hormone suppression. 
Table 2 BMD of the lumbar spine $\left(\mathrm{g} / \mathrm{cm}^{2}\right)$ in DTC patients with TSHS and postmenopausal controls

\begin{tabular}{l|l|l|l|l}
\hline Follow-up & TSHS & $\begin{array}{l}\text { Postmenopausal } \\
\text { controls }\end{array}$ & t-value & P-value \\
\hline Baseline & $1.05 \pm 0.16$ & $1.06 \pm 1.21$ & -0.315 & 0.753 \\
6 months & $1.03 \pm 0.17$ & $0.98 \pm 0.16$ & 1.37 & 0.17 \\
12 months & $1.04 \pm 0.14$ & $1.04 \pm 0.17$ & -0.128 & 0.89 \\
24 months & $1.03 \pm 0.15$ & $1.06 \pm 0.27$ & -0.547 & 0.59 \\
\hline
\end{tabular}

Notes: TSHS and postmenopausal controls: baseline vs 6 months, $t=1.209, P=0.228$; $t=2.018, P=0.05$; baseline vs 12 months: $t=0.602, P=0.55 ; t=0.42, P=0.67$; baseline vs 24 months: $t=0.97, P=0.33 ; t=0.004, P=0.997$. Data are presented as mean $\pm S D$. Abbreviations: BMD, bone mineral density; DTC, differentiated thyroid carcinoma; TSHS, thyroid-stimulating hormone suppression.

BMD can be measured by DXA, single-photon absorptiometry, dual-photon absorptiometry, quantitative computed tomography, ${ }^{19}$ ultrasound $^{20}$ and high-resolution peripheral quantitative computed tomography. ${ }^{21} \mathrm{DXA}$ is the most commonly used gold standard for BMD evaluation and was used in the study. ${ }^{10,22}$ Many factors affect BMD in DTC patients including TSHS, postmenopausal, inactive lifestyle and others. The majority of patients were retired from their work during the present study. In our study, the age- (postmenopausal women), sex- and disease-matched controls were used for comparison. Thus, the effects of estrogen deficiency and lifestyle in the present study population were negligible.

Similar to other studies which have not confirmed a negative effect of TSHS, ${ }^{7,14-18}$ our results found that TSHS is not a significant risk factor for bone loss in postmenopausal women with DTC after 2 years of follow-up. This finding is contrary to the results from smaller samples. , $10,12-14,23,24^{2}$ The suppressive doses of $\mathrm{LT}_{4}$ are unlikely ${ }^{25}$ to affect BMD

Table 3 The number of osteopenia and osteoporosis in DTC patients with TSHS and postmenopausal controls during the 2-year follow-up

\begin{tabular}{l|l|l|l|l|l}
\hline & Total & $\begin{array}{l}\text { Number of } \\
\text { osteopenia }\end{array}$ & $\begin{array}{l}\text { Number of } \\
\text { osteoporosis }\end{array}$ & $\chi^{2}$ & P-value \\
\hline TSHS & \multicolumn{5}{|l}{} \\
\hline Baseline & 154 & 57 & 8 & & \\
6 months & 154 & 66 & 12 & 1.48 & 0.14 \\
I2 months & 154 & 60 & 11 & 0.69 & 0.49 \\
24 months $^{\mathrm{a}}$ & 152 & 90 & 13 & 4.3 & $<0.0001$ \\
\hline
\end{tabular}

\section{Postmenopausal controls}

\begin{tabular}{l|l|l|l|l|l}
\hline Baseline & 71 & 23 & 7 & & \\
6 months & 70 & 27 & 8 & 0.92 & 0.36 \\
I2 months & 69 & 22 & 8 & 0.07 & 0.94 \\
24 months & 68 & 23 & 9 & 0.41 & 0.68
\end{tabular}

Notes: aSignificant difference in the number of osteopenia and osteoporosis patients at 24 months $\left(\chi^{2}=2.88, P=0.004\right)$ between the TSHS and postmenopausal control groups; no significant difference in the number of osteopenia and osteoporosis patients at 6 and 12 months.

Abbreviations: DTC, differentiated thyroid carcinoma; TSHS, thyroid-stimulating hormone suppression.

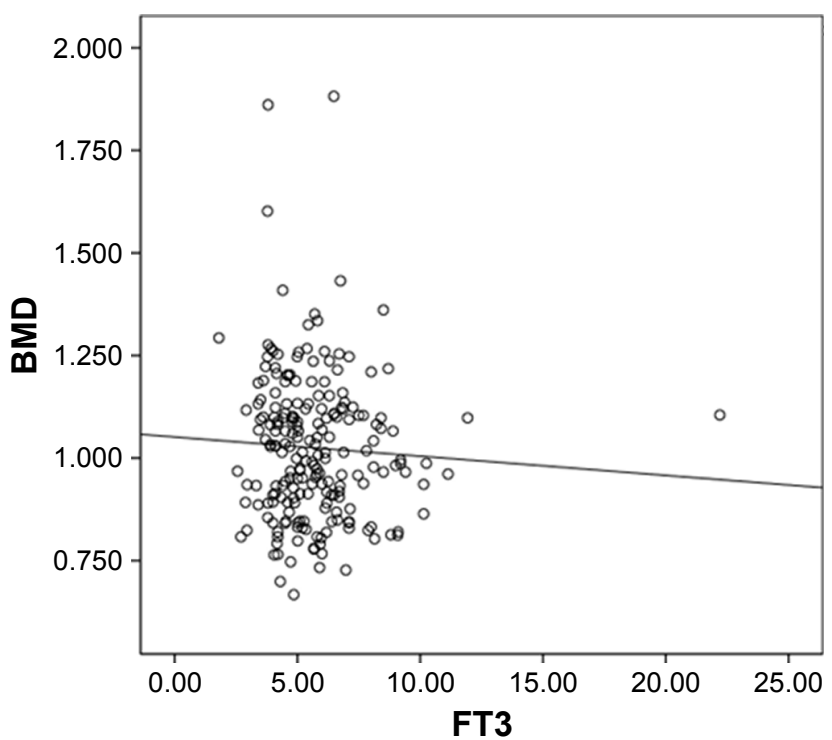

Figure I Pearson analysis found that there was no significant correlation between BMD and FT3 ( $r=-0.054, P=0.437)$.

Abbreviations: BMD, bone mineral density; FT3, triiodothyronine.

in premenopausal women but likely led to reductions in BMD for up to 10 years in postmenopausal women. ${ }^{8}$ The conflicting results may be due to the different follow-up time, daily calcium intake or sunlight exposure as well as characteristics of the different control groups. ${ }^{26}$ But one of the most important factors may be the different TSH levels observed in all those studies, TSH $<0.5 \mu \mathrm{IU} / \mathrm{mL}$ $(0.005-1.5),{ }^{10,27} \mathrm{TSH}<0.1 \mu \mathrm{IU} / \mathrm{mL},{ }^{18} \mathrm{TSH} 0.1-0.5 \mu \mathrm{IU} / \mathrm{mL},{ }^{11}$ $\mathrm{TSH}<0.01 \mu \mathrm{IU} / \mathrm{mL},{ }^{9} \mathrm{TSH} \leq 0.03 \mu \mathrm{IU} / \mathrm{mL},{ }^{1}$ etc. According to American Thyroid Association 2015 and Chinese guidelines

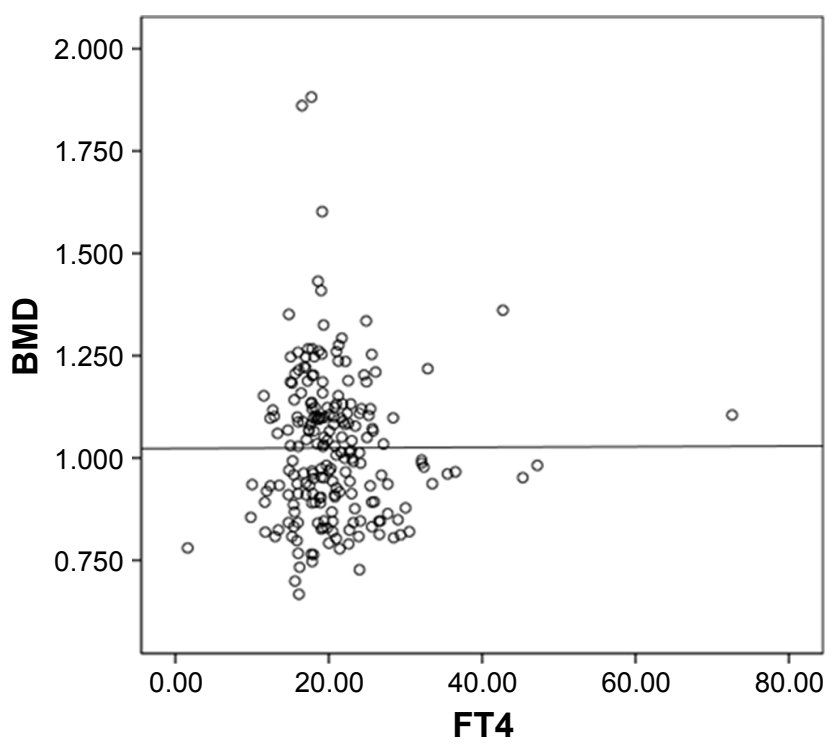

Figure 2 Pearson analysis found that there was no significant correlation between $\mathrm{BMD}$ and FT4 $(r=0.003, P=0.986)$.

Abbreviations: BMD, bone mineral density; FT4, free thyroxine. 
$2012,{ }^{3,4}$ the $\mathrm{TSH}$ target was kept at $<0.1 \mu \mathrm{IU} / \mathrm{mL}$, $0.1-0.5 \mu \mathrm{IU} / \mathrm{mL}$ and $0.5-1 \mu \mathrm{IU} / \mathrm{mL}$ for patients with high-, intermediate- and low-risk DTC, respectively. The TSH assay reference in our laboratory was $0.3-0.5 \mu \mathrm{IU} / \mathrm{mL}$, therefore TSH below $0.3 \mu \mathrm{IU} / \mathrm{mL}$ was regarded as the suppression group.

In agreement, our data also showed significant difference in the prevalence of osteoporosis and osteopenia at the 2-year follow-up, which may be due to the inhibitions of osteoblastogenesis, ${ }^{15}$ osteoblasts' differentiation and stimulation of apoptosis of mature osteoclasts. ${ }^{28,29}$ TSHS may also have a differential impact on diverse bone sites. The reduction in BMD at the lumbar spine was $1.9 \%$ which was slightly lower than that reported (7\%) at the 2-year follow-up and $5 \%$ at the hip. ${ }^{30}$ Osteopenia was found more frequently in cortical bone than in trabecular bone. ${ }^{31}$ Hyperthyroidism seems to affect the cortical bone in the hip and forearm more so than in the trabecular bone in the spine. ${ }^{16}$ Increased FT4 levels within the normal range may cause deterioration in trabecular bone microarchitecture. ${ }^{32}$ No significant correlation between BMD and FT3 and FT4 was found in our group. In addition, the BMD of femoral bone was not monitored in our study. The longer duration of TSHS with decreased vertebral bone strength by altering trabecular bone score (TBS) rather than BMD in postmenopausal DTC patients was observed. ${ }^{33}$

Calcium and vitamin D supplementation with 1,200 mg calcium intake per day and $0.25 \mu \mathrm{g}$ vitamin $\mathrm{D}$ may prevent bone loss during the early post-thyroidectomy period which is in agreement with our study. ${ }^{11}$ Long-term hyperthyroidism is an established risk of osteoporosis and fractures. ${ }^{6,7}$ Rosen et $\mathrm{al}^{27}$ reported that bisphosphonates had a significant increase in BMD for DTC patients on TSHS. Therefore, BMD should be followed up regularly, and the bisphosphonates treatment may be indicated in DTC patients who had TSHS and osteoporosis.

\section{Conclusion}

Our 2-year follow-up data indicated that TSHS had little effect on BMD in postmenopausal women with DTC. Large population with at least 5-year follow-up should be further investigated. BMD should be followed up regularly. Bisphosphonate drugs may be suggested for postmenopausal DTC women with osteoporosis at the beginning of TSHS. The limitations of the study are the retrospective design and lack of a BMD assessment in hip joint.

\section{Disclosure}

The authors report no conflicts of interest in this work.

\section{References}

1. Kung AW, Yeung SS. Prevention of bone loss induced by thyroxine suppressive therapy in postmenopausal women: the effect of calcium and calcitonin. J Clin Endocrinol Metab. 1996;81(3):1232-1236.

2. Greenspan SL, Greenspan FS, Resnick NM, Block JE, Friedlander AL, Genant HK. Skeletal integrity in premenopausal and postmenopausal women receiving long-term L-thyroxine therapy. Am J Med. 1991; 91(1):5-14.

3. Chinese Society of Endocrinology. [Diagnosis and treatment guideline for thyroid nodules and differentiated cancer]. Cancer Clin China. 2012; 17:1249-1272. Chinese.

4. Haugen BR, Alexander EK, Bible KC, et al. 2015 American Thyroid Association Management Guidelines for Adult Patients with Thyroid Nodules and Differentiated Thyroid Cancer: The American Thyroid Association Guidelines Task Force on Thyroid Nodules and Differentiated Thyroid Cancer. Thyroid. 2016;26(1):1-133.

5. Biondi B, Cooper DS. Benefits of thyrotropin suppression versus the risks of adverse effects in differentiated thyroid cancer. Thyroid. 2010; 20(2):135-146.

6. Franklyn JA, Maisonneuve P, Sheppard MC, Betteridge J, Boyle P. Mortality after the treatment of hyperthyroidism with radioactive iodine. N Engl J Med. 1998;338(11):712-718.

7. Vestergaard P, Rejnmark L, Weeke J, Mosekilde L. Fracture risk in patients treated for hyperthyroidism. Thyroid. 2000;10(4):341-348.

8. Uzzan B, Campos J, Cucherat M, Nony P, Boissel JP, Perret GY. Effects on bone mass of long term treatment with thyroid hormones: a metaanalysis. J Clin Endocrinol Metab. 1996;81(12):4278-4289.

9. Sugitani I, Fujimoto Y. Effect of postoperative thyrotropin suppressive therapy on bone mineral density in patients with papillary thyroid carcinoma: a prospective controlled study. Surgery. 2011;150(6): 1250-1257.

10. Tournis S, Antoniou JD, Liakou CG, et al. Volumetric bone mineral density and bone geometry assessed by peripheral quantitative computed tomography in women with differentiated thyroid cancer under TSH suppression. Clin Endocrinol. 2015;82(2):197-204.

11. Kim MK, Yun KJ, Kim MH, et al. The effects of thyrotropin-suppressing therapy on bone metabolism in patients with well-differentiated thyroid carcinoma. Bone. 2015;71:101-105.

12. Flynn RW, Bonellie SR, Jung RT, MacDonald TM, Morris AD, Leese GP. Serum thyroid-stimulating hormone concentration and morbidity from cardiovascular disease and fractures in patients on long-term thyroxine therapy. J Clin Endocrinol Metab. 2010;95(1):186-193.

13. Morris MS. The association between serum thyroid-stimulating hormone in its reference range and bone status in postmenopausal American women. Bone. 2007;40(4):1128-1134.

14. Kim CW, Hong S, Oh SH, et al. Change of Bone Mineral Density and Biochemical Markers of Bone Turnover in Patients on Suppressive Levothyroxine Therapy for Differentiated Thyroid Carcinoma. J Bone Metab. 2015;22(3):135-141.

15. Lee MY, Park JH, Bae KS, et al. Bone mineral density and bone turnover markers in patients on long-term suppressive levothyroxine therapy for differentiated thyroid cancer. Ann Surg Treat Res. 2014;86(2):55-60.

16. Reverter JL, Holgado S, Alonso N, Salinas I, Granada ML, Sanmartí A. Lack of deleterious effect on bone mineral density of long-term thyroxine suppressive therapy for differentiated thyroid carcinoma. Endocr Relat Cancer. 2005;12(4):973-981.

17. Heijckmann AC, Huijberts MS, Geusens P, de Vries J, Menheere PP, Wolffenbuttel BH. Hip bone mineral density, bone turnover and risk of fracture in patients on long-term suppressive L-thyroxine therapy for differentiated thyroid carcinoma. Eur J Endocrinol. 2005;153(1):23-29.

18. Ricken R, Bermpohl F, Schlattmann P, et al. Long-term treatment with supraphysiological doses of thyroid hormone in affective disorders - effects on bone mineral density. J Affect Disord. 2012; 136(1-2):e89-e94.

19. Murphy E, Williams GR. The thyroid and the skeleton. Clin Endocrinol. 2004;61(3):285-298. 
20. Chin KY, Ima-Nirwana S, Mohamed IN, Aminuddin A, Johari MH, Ngah WZ. Thyroid-stimulating hormone is significantly associated with bone health status in men. Int J Med Sci. 2013;10(7):857-863.

21. Moser E, Sikjaer T, Mosekilde L, Rejnmark L. Bone Indices in Thyroidectomized Patients on Long-Term Substitution Therapy with Levothyroxine Assessed by DXA and HR-pQCT. J Thyroid Res. 2015; 2015:796871-796879

22. Sheu Y, Zmuda JM, Boudreau RM, et al. Bone strength measured by peripheral quantitative computed tomography and the risk of nonvertebral fractures: the osteoporotic fractures in men (MrOS) study. J Bone Miner Res. 2011;26(1):63-71.

23. El Hadidy el HM, Ghonaim M, El Gawad SSH, El Atta MA. Impact of severity, duration, and etiology of hyperthyroidism on bone turnover markers and bone mineral density in men. BMC Endocr Disord. 2011; $11: 15$.

24. Karner I, Hrgović Z, Sijanović S, et al. Bone mineral density changes and bone turnover in thyroid carcinoma patients treated with supraphysiologic doses of thyroxine. Eur J Med Res. 2005;10(11):480-488.

25. Quan ML, Pasieka JL, Rorstad O. Bone mineral density in well-differentiated thyroid cancer patients treated with suppressive thyroxine: a systematic overview of the literature. J Surg Oncol. 2002;79(1):62-70.

26. de Melo TG, da Assumpção LV, Santos AO, Zantut-Wittmann DE. Low BMI and low TSH value as risk factors related to lower bone mineral density in postmenopausal women under levothyroxine therapy for differentiated thyroid carcinoma. Thyroid Res. 2015;8:7.
27. Rosen HN, Moses AC, Garber J, et al. Randomized trial of pamidronate in patients with thyroid cancer: bone density is not reduced by suppressive doses of thyroxine, but is increased by cyclic intravenous pamidronate. J Clin Endocrinol Metab. 1998;83(7):2324-2330.

28. Sun L, Davies TF, Blair HC, Abe E, Zaidi M. TSH and bone loss. Ann N Y Acad Sci. 2006;1068:309-318.

29. Abe E, Marians RC, Yu W, et al. TSH is a negative regulator of skeletal remodeling. Cell. 2003;115(2):151-162.

30. Blum MR, Bauer DC, Collet TH, et al. Subclinical thyroid dysfunction and fracture risk: a meta-analysis. JAMA. 2015;313(20):2055-2065.

31. Ongphiphadhanakul B, Alex S, Braverman LE, Baran DT. Excessive L-thyroxine therapy decreases femoral bone mineral densities in the male rat: effect of hypogonadism and calcitonin. J Bone Miner Res. 1992; 7(10):1227-1231.

32. Hwangbo Y, Kim JH, Kim SW, et al. High-normal free thyroxine levels are associated with low trabecular bone scores in euthyroid postmenopausal women. Osteoporos Int. 2016;27(2):457-462.

33. Moon JH, Kim KM, Oh TJ, et al. The Effect of TSH Suppression on Vertebral Trabecular Bone Scores in Patients With Differentiated Thyroid Carcinoma. J Clin Endocrinol Metab. 2017;102(1):78-85.
OncoTargets and Therapy

\section{Publish your work in this journal}

OncoTargets and Therapy is an international, peer-reviewed, open access journal focusing on the pathological basis of all cancers, potential targets for therapy and treatment protocols employed to improve the management of cancer patients. The journal also focuses on the impact of management programs and new therapeutic agents and protocols on

\section{Dovepress}

patient perspectives such as quality of life, adherence and satisfaction The manuscript management system is completely online and includes a very quick and fair peer-review system, which is all easy to use. Visit http://www.dovepress.com/testimonials.php to read real quotes from published authors. 